TITE:

AUTHOA(S):

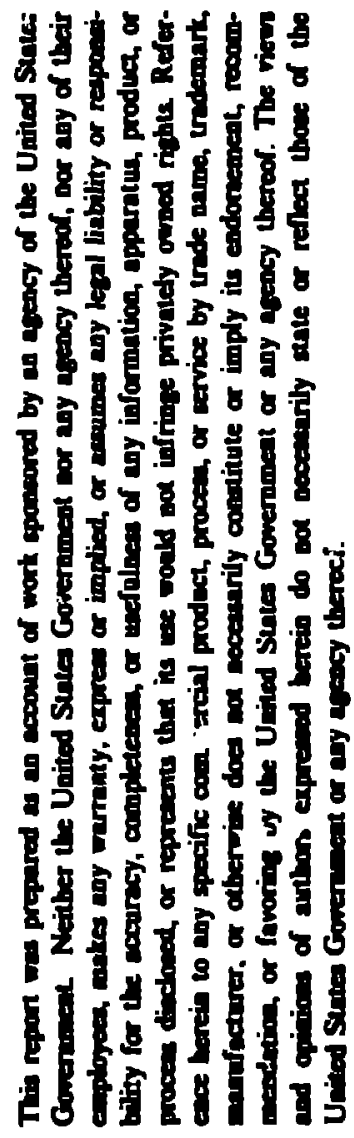

THE LOS ALAMOS ACCELERATOR CODE GROUP *

Frank L. Krawczyk

James H. Billen

Robert D. Ryne

Harunori Takeda

Lloyd M. Young
AOT-1

AOT-1

AOT-1

AOT-1

AOT-1
SUBNITED TO:

1995 Particle Accelerator Conference and International Conference on High-Energy Accelerators

Hyatt Regency Hotel, Dallas, Tx, May 1-5, 1995

(O)

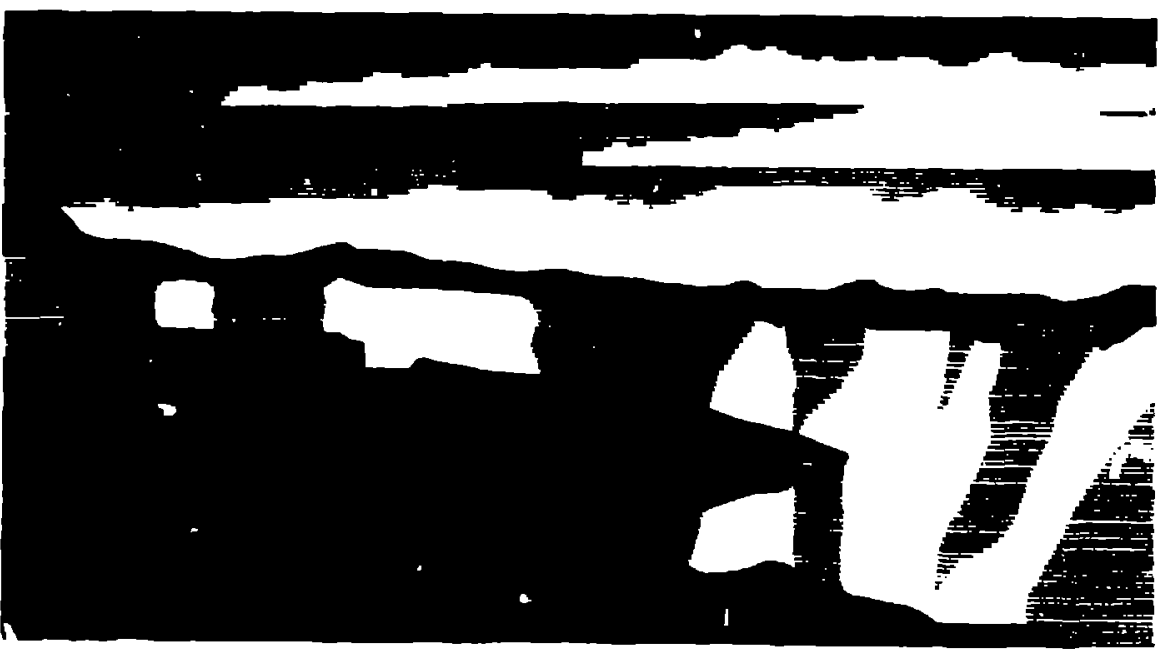

NATIONAL LABORATORY

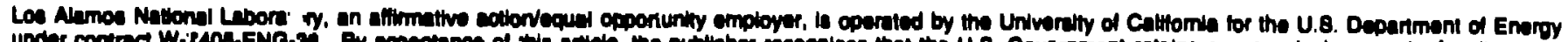

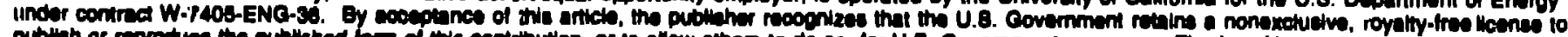

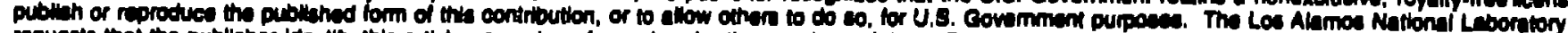

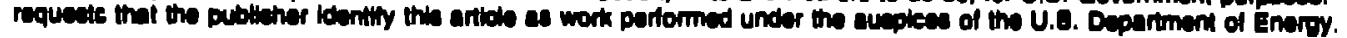




\title{
THE LOS ALAMOS ACCELERATOR CODE GROUP *
}

\author{
Frank L. Krawczyk, James H. Billen, Robert D. Ryne, Harunori Takeda, Lloyd M. Young, AOT-1. \\ MS H817, Los Alamos National Laboratory, Los Alamos, NM 87545 USA
}

\begin{abstract}
The Los Alamos Accelerator Code Group (LAACG) is a natjonal resource for members of the accelerator community who use and/or develop software for the deaign and analysis of particle accelerators, beam transport systems, light sources, storage rings, and components of these sys tems. Below we deacribe the LAACG's activities in high performance computing, maintenance and enhancement of POISSON/SUPERFISH and related codes and the dissemination of information on the INTERNET.
\end{abstract}

\section{POISSON/SUPERFISH}

The LAiCG supports the PC version of POISSON, SUPERFISH and PANDIRA, currently used by several hundred people. POISSON/SUPERFISH is a collection of programs for calculating static magnetic and electric fields and radio-frequency electromagnetic fields in either 2-D Cartesian coordinates or axially symmetric cylindrical coordinates. The programs generate a triangular mesh fitted to the boundaries of different materials in the problem geometry. The original version of POISSON/SUPERFISH was written in the early 1970 s by R. F. Holsinger from theory developed by Klaus Halbach[2]. An older UNDX version of these codes is also still available, but this version has not had any significant development in the pi st few years. At PAC93 [1] we described a new SUPERFISH root finder and sorne other improvements that we had implemented in the $\mathrm{PC}$ version.

Diring the past two years, we have made about 120 changes in the codes which include new features, bug fixes, and other improvements. The most significant of these changes include

- Run-time memory allocatiou of all mesh-point arrays and temporary data,

- A more robust meshing algorithm in AUTOMESH,

- A new Geld-interpolation algorithm that satisfles boundary conditions for if, magnetostatic, and electrostatic problems,

- Automation and mouse support in the plotting program VGAPLOT,

- HPGL and PostScript graphlcs support in all plotting codes,

- Conflguration options in fle SF.INI,

- Up to 10-line problem descriptions for better record keeping,

- A utllity program for examining contents of the solution flle,

-Work supported by the U.S. Depertment of Enercy, Office of High Energy Phyulca, Office of Sclentific Compullng, and Office of Nuclear Phyales
- For program developers, a linkable field-interpolation module for use in user-developed post processors and source code for reading the solution fles.

Run-time memory allocation means that the computer's available memory is the only limit on the maximum problem size. The codes require $3 \mathrm{MB}$ or more of memory: The more memory available, 1 ie larger the number of mesh points the codes can use to sol . - problems. We recommend at least $8 \mathrm{MB}$ of installed RAM plus at least $100 \mathrm{MB}$ of disk apace for temporary data storage. If there is insuffcient RAM, SUPERFISH and PANDIRA write temporary data to disk. The size of the temporary tile depends upon the number of mesh points and the shape of the problem geometry.

The code distribution now includes the programs PANDIRA, a isrect solver version of POISSON that also can handle permanent-magnet materials, and FORCE for calculating the force on coils and iron elements in maguetostatic problems. We hope to add the optimizing code MIRT to the package later this year. The complete PC SUPERFISH listribution contains 26 executable codes, 25,000 lines of on-liue documentation, plus input files for about 50 sample prc tems. These examples include all of the sample problems from the Reference Manual and User's Guide [3]. Documentation specific to the PC version resides on disk. Prograuss are provided to display the documentation ur produce indexed, paginated files suitable for primting. The installation requires about $13 \mathrm{MB}$ of disk space. The cudes are compiled from approximately 590,000 lines of FORTRAN source code.

We distribute the PC package, which includes an iustallation program, by interget FTP or, upon request, un either 3.5-inch or 5.25-inch floppy diskettes. Fostage for mailing diskettes and printed manuals is paid by Los Alanos National Laboratory. Customs charges, if any, are paid by the recipient. Registered users receive notiflcation of updates and bug fixes by Emall. New users can register and request access to our FTP seiver by sending their postal address, phone and fax numbers to SUPERFISHGLANL.GOV.

\section{HIGH PERFORMANCE COMPUTING}

Accelerator-driven technologiea are now being proposed to solve problems of national and International importance. These technologies have both ecouomic and environmental implleations. They include Accelerator Production of Tritlum (APT). Accelerator Transmutation of Waste (ATW), Accelerator Based Conversion of plutonium (ABC), accelerator-driven production of spallation ueutrons for materials sclence and biological-science research, accelerator driven production of neutrons for fusioumaterials testing, and acceleratur-driven faslou-energy syb- 
tems. All of these projects require next-generation linear accelerntors that operace with extremely low beam loss. A

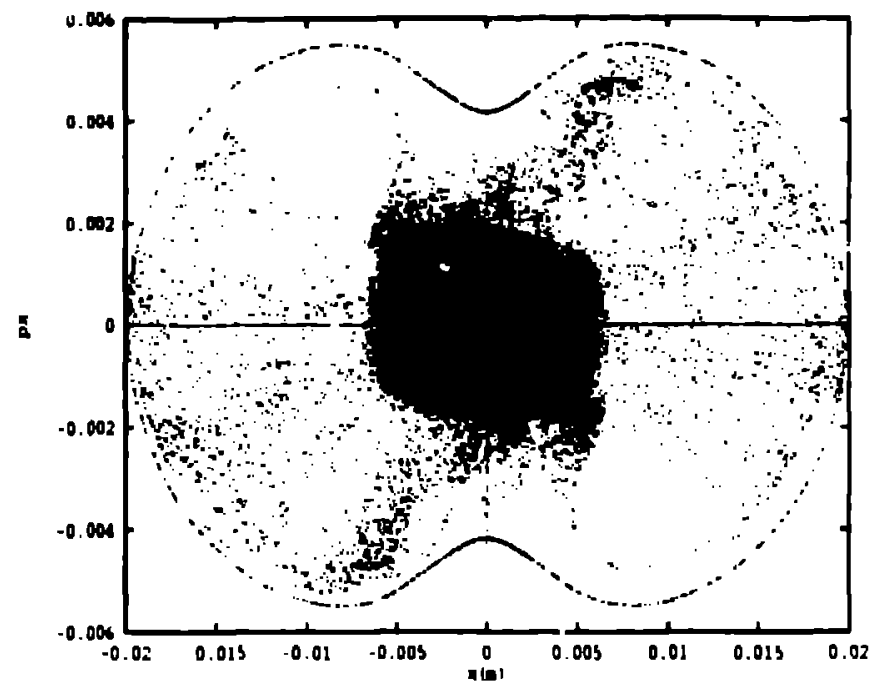

Figure. 1. Beam phase space from a 2 milling particle simulation on the CM-5 (65536 points are plotted). The outer peanut-shaped set of points were obtained from the particle-core model.

maximum beam loss in the accelerator of roughly 10 parts per mlllion is required to assure hands-on maintenance capability. Bean loss at this low level is due to the presence of a very low density beam halo al large transverse dis tances from the core. In order to predict beam halo with confidence, one must perform numerical simulations of unp:ecedented resolution. For example, to have a $10 \%$ confidence in the number of halo particles, one would need to perform a simulation that resulted in roughly 100 particles in the halo; but if the halo accounted for 10 parts per million, this would mean that the simulation would require a total of 10 million particles. This is a major step beyond the linac simulations of the 1980 s that typically used only 10,000 particles.

The LAACG has had much success in developlng such a high-resolution accelerator-modeling capabllitj[4]. Starting in 1994, we began using the masively parallel CM-5 at the Advanced Computing Laboratory at LANL to perform beam-halo simulations. The tools we are developing to model next-generation accelerators provide us with a means to test now designs, test theoretical models, and optimize our designs.

We have developed and used a two-dimensional ParticleIn-Cell code to model long beams in a variety of focusing systems. Using our code, we roulinely perform simulation. with several to ten mlllon particles. One of our early appllcatlons was to model a mismatched KV beam In a constant focusing channel. We found that when the beam was uustable the charge redistributed itself in such a way that, though a halo was formed, It was bounded, and furthermore the extent of the halo was in excellent agreement with a the-

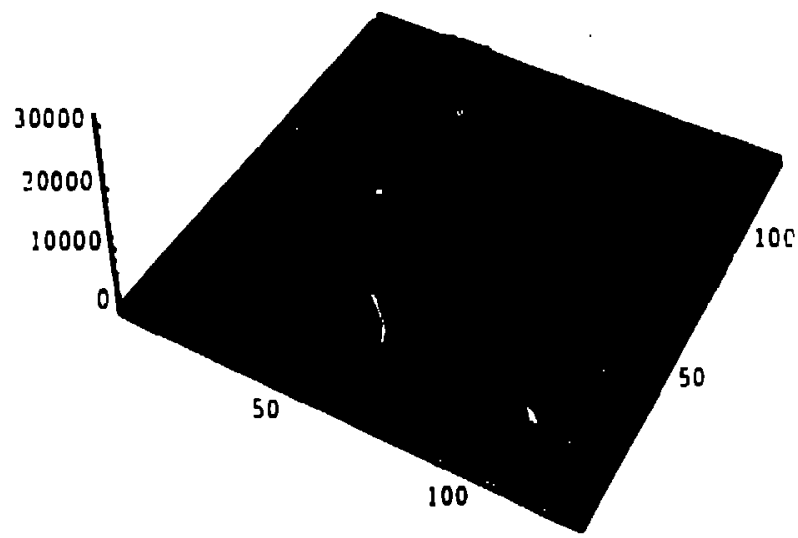

Figure. 2. Outp: ‘t trom a direct Vlasov/Poisson simulation. The 4-dimensional distribution function was integrated over $p_{z}$ and $p_{\text {, }}$ to obtrin the beam density on a $128 \times 128$ grid.

oretical model called the particle-core model of halo evolution in mismatched beams. This is shown in Figure 1. We have also performed simulations that dealt with the coutroversial issue of whether of not quadrupole focusing can cause significant halo formation for matchef beams. Our results indicate that breathing due to quadrupole focusing will not be a problem in the physics regime of the projects described above, where the tune depression is at worst approximately 50\%. Begides developing particle simulatiou codes we are also studying other approaches to modeling and predicting beam halo. For example, we have developed a two-dimensional (four-dimensional phase space) direct Vlasov-Poisson simulation code. We have performed very high resolution simulations on a $128 \times 128 \times 128 \times 128$ grid, for a total of 268 million grid points. A typical simulatiou of a beam in a quadrupole channel is shown in Figure 2.

At present multi-million particle simulations are the best meang we bave to quantitatively predict extremely low beain loss, so they are crucial to lunding support to the validity of proposed designs.

Since all of our codes are written in the CM FORTRAN program language (a FORTRAN90-like language), it will be easy to port them to other platforms that support the data parallel paradigm. So far our activlties have emphasized two-dimensional modeling. Our future goals are aimed at modeling three-dimensional (l.e. bunched) beams Including acceleration.

\section{INFORMATION RESOURCES FOR THE ACCELERATOR COMMUNITY ON THE INTERNET}

In October 1994 the LAACG began making Information avallable vla the World WIde Web (WWW). The docu- 
ments can be arcessed at the addreas:

<hlip://ourw.atdiv.lanl.gov/dac/laceg/codehome.htmis. The published documents provide a variety of informaition of interest to the accelerator as weil as other scientific communities. The documents include:

- information about the LAACG and its services,

- general information of interest for the accelerator community,

- extensive list of links to accelerator laboratories and institutes worldwide (approximately 100),

- information related to the field of electromagnetic field calculations and information on other computational tools for accelerator phyaics,

- online versions oi the previously published Accelerator Code Compendium from 1990 and a new up-to-dare Code Compendium,

- excerpts from the user-documentation of the codes distributed by the LAACG,

- an online information service for the 1995 Particle Acclerator Conference in Dallas, Texas.

This new service is well accepted by the scientific community. This is documented by an average number of 235 accesses per month with an approximate unonthly use of 1800 documents. $64 \%$ of the accesses are from within the USA and Canada. The rest is predominantly from Europe and Japan (based on activities before April 19, 1995).

Table 1: Most Frequently Used Services

\begin{tabular}{|c|l|c|}
\hline & Service & accesses \\
\hline 1. & PAC-Conference & 1242 \\
2. & Code Group Services & 419 \\
3. & Electromagnetics & 297 \\
4. & Iist of Accelerators & 224 \\
5. & General infornation & 209 \\
6. & POISSON/SUPERFISH & 163 \\
7. & Old Code Compendium & 156 \\
8. & P/S Userguide & 119 \\
9. & New Code Compendium & 109 \\
\hline
\end{tabular}

We encourage the community's interaction to help us inprove the services provided on the WWW. Our major interest lles in the extenaion of a new online Cude Compendium. The last printed version is from May' 1990. With the rapid development of codes and computers this compendium is outdated. For this new compendium, the LAACG needs the community's input. At the conference questionuaire are avallable to enter new codes and update information on entrles in the old compendium.

We also set up a FTP-server that allowe the community to get the codes distrlbuted by the LAACG over the network without extensive interaction with us. We still recommend subecribing to the POISSON/SUPERFISH malling lits. Thlo to the only way to become aware of bugs, code corrections or code upgrades. The FTP-address can be oltained from the new WTW online Code Compendium.

Another activity of the code group on the DNTERNET iu mid 1993 led to the creation of a USENET discussion group on accelerator physics. The group sci.physics.acrelerators is a discussion forum on accelerator physics, beam physics and general contacts between researchers.

Lastly, at the request of the LAACG an electronic preprint service centered on accelerator phyaics has been created. Such forums allow access to preprints of publicatioss before they are available in paperbound journals. This service is availabe on the WWW at the L'RL: <http://roux.lanl.gov/> as well as by electronic mail and FTP.

\section{References}

[1] J. H. Billen and L. M. Young, "POISSON/SUPERFISH on PC Compatibles," Pruceedings of the 1993 Particle Accelerator Conference, Vol. 2, p. 790.

[2] K. Halbach, K.F. Honsinger, "SUPERFISH - A Computer Program fror Evaluation of RF Cavities with Cylindrical Symunetry", Particle Acelerator 7(4), 213222 (1976)

[3] Reference Manual for the POISSON/SUPERFISH Group of Codes, Los Alamos National Laboratory Rrport LA-UR-87-126 (1987); and User's Guide for the for the POISSON/SUPERFISH Group of Codes, Lus Aiamos National Laboratory Report LA-UR-87-115 (1987).

[4] R. Ryue and T. Wangler, "Recent Results in Aualysis and Simulation of Beam Halo," Interuational Conference on Accelerator Driven Transmutation Techuolugies and Applications, Las Vegas, NV (July 1994) 